\title{
Turning one lab's trash into another's treasure
}

Miguel Omar Velardez was bracing himself for his return to Argentina after years at richly funded Harvard University. He had a position

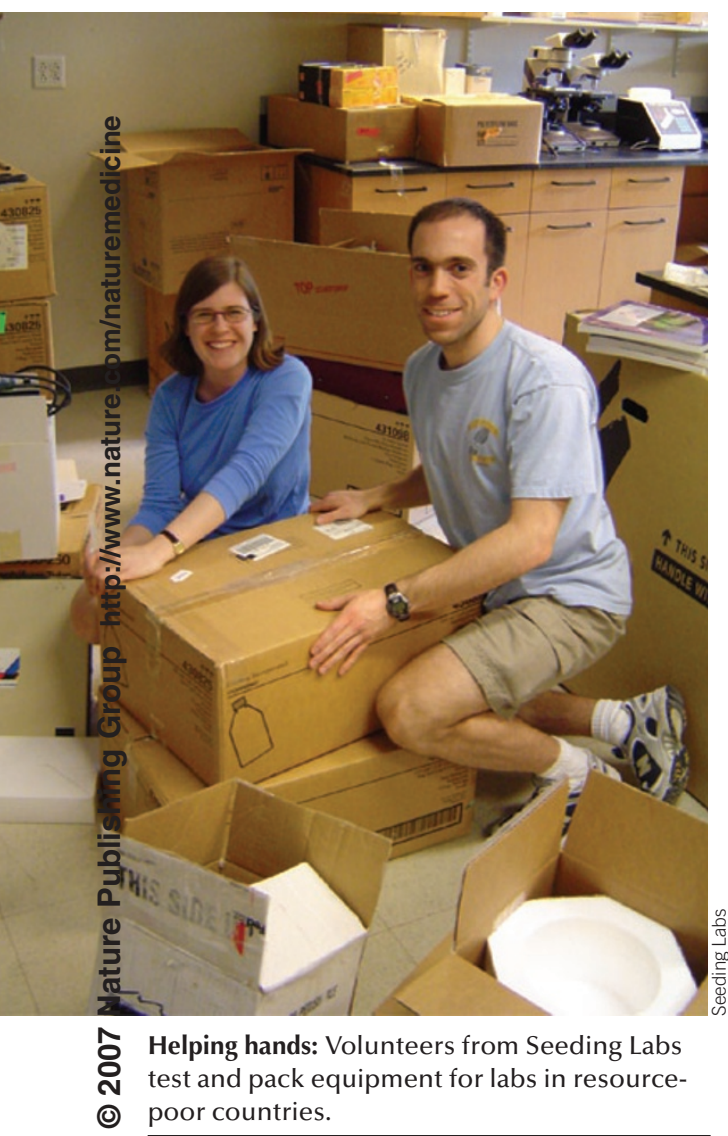

lined up at the University of Buenos Aires, and the Argentinian government was paying for his move, but start-up funds were not a part of the package. "They say, 'we love you, we love your research, this is your place: 36 square meters of empty lab and no grants so far."”

When Velardez heard from a friend that he could get used lab supplies for a pittance, he jumped at the chance. Seeding Labs, a nonprofit launched in 2002 by a group of Harvard graduate students, found him a titerplate shaker, a stirring hot plate and a UV illuminator, all discarded by Doug Melton's lab at the university.

Two graduate students came by and picked up the equipment, and three others tested the pieces to see if they worked. By the time you read this article, the equipment will be in Argentina, helping Velardez work out the role of the protein neuregulin in puberty.

"I want to demonstrate that with just a little help, you can do very good science here in a developing country," says Velardez.

The help Velardez received is a natural extension of what many researchers in resourcepoor countries already do-accept ad hoc donations from colleagues in rich countries. Since the nonprofit's launch, Seeding Labs volunteers have donated old but serviceable lab equipment worth about $\$ 300,000$ to 11 labs, spending only $\$ 8,000$, mostly on shipping.

"We had all worked in labs in developing countries, we had seen firsthand what it means to do science in these countries," says cofounder Nina Dudnik, a molecular biology student at Harvard's medical school who has spent time working in the Ivory Coast. "We walked the halls at night and saw the trash that people were putting out, and half of it was usable lab equipment. It seemed obvious."

The 70 volunteers collect water baths, vortexes, PCR machines, pipette tips and the like, test the machinery and make simple repairs. Funding comes from the New York-based 'angel investor' Echoing Green, Harvard, and the Sustainable Sciences Institute in California (see page 1132). Seeding Labs is seeking more funds to expand and establish a scientific advisory board to help vet and prioritize requests.

The group's recipients were initially labs in South America that were working with the Sustainable Sciences Institute and have expanded to include Paul Farmer's Haitian charity Partners in Health and Congo Protestant University in Kinshasa, which opened a medical school last year.

"There are about 20 organizations in the country that donate surplus hospital equipment," says Melvin J. Loewen, a former president of the university who now coordinates support for it from his home in Indiana. "Our frustration was that we couldn't find anything that was dealing with the chemistry, biology and physics of pre-med. I think what these grad students are doing in the Boston area is excellent."

Emma Marris, Columbia, Missouri

Sometimes the simplest solutions are the best. Scientists have transformed a blender into a centrifuge (a), recycled gloves (b) used a soda bottle as a make-do ice bucket (c), devised a simpler flow cytometer (d) and invented a tip washer for rinsing out pipet tips (e).

a

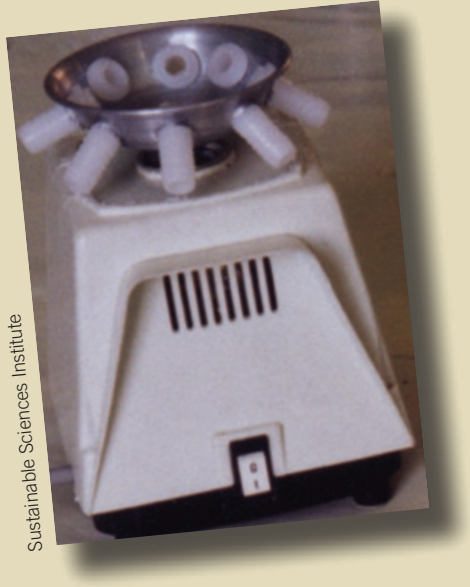

C

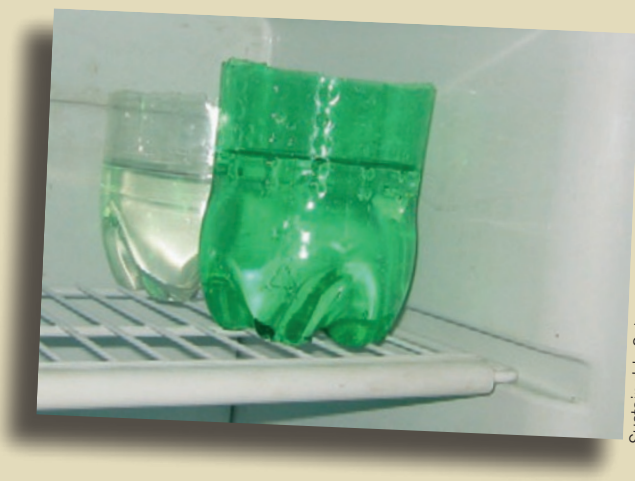

b

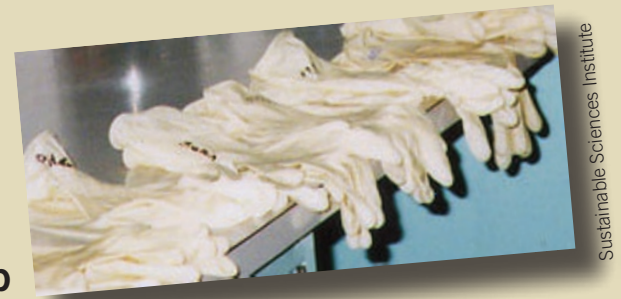

